\title{
Endoscopic surgery through single-port incision: time for a trial?
}

\author{
Alberto Arezzo • Mario Morino
}

Published online: 7 May 2011

(C) Springer Science+Business Media, LLC 2011

It has been at least 30 years now that it was declared that one of the goals of surgery is the reduction of treatment invasiveness [1]. This pushed research in technology to define new techniques that proved safe and effective and are today considered gold standard treatments. Good examples are laparoscopic cholecystectomy for symptomatic gallstones and transanal endoscopic microsurgery for adenomas of the upper and middle rectum.

More recently, natural orifice transluminal endoscopic surgery (NOTES) has been brought to the attention of the lay media and literature after the first clinical reports. The concept was introduced in 2004 [2] and feasibility was tested extensively in animal experiments in the following years. New scientific societies and dedicated committees within existing scientific organs were born with the declared aim of regulating research activity through sponsorships and registers, but the goal was never reached completely. After less than 3 years, the race for the first cholecystectomy under NOTES conditions in a human being had run its course. Since then, many authors have reported various personal case series, while many others presented consistent research activity in vitro or in vivo, but it seems evident that two different branches of research were being defined [3]. The first is what we would call endoscopic access natural orifice surgery (EA-NOS), which includes all procedures truly performed through natural orifices. It had the goal of designing new platforms for surgery to be brought within the human body to recreate safe surgical conditions. The evident difficulties in obtaining such an environment with guaranteed ease of use,

A. Arezzo $\cdot$ M. Morino $(\bowtie)$

Digestive, Colorectal and Minimal Invasive Surgery, University of Turin, c.so Dogliotti 14, 10126 Torino, Italy

e-mail: mario.morino@unito.it safety, and efficacy reduced the interest in this field to a mere research activity. A few clinical applications were described consisting of hybrid procedures, i.e., procedures that were performed basically under laparoscopic conditions with the help of flexible instruments inserted through natural orifices. In fact, a recent large meta-analysis of the NOTES literature [4] focusing on various surgical intraabdominal procedures, all ascribable to EA-NOS, concluded that no human studies were found satisfactory for the inclusion criteria, for scarce disposable evidence, minor safety, and efficacy compared to laparotomy and laparoscopy. The recommendation that human procedures should first pass through hybrid NOTES surgery, under strict guidelines, and in apposite controlled registers was later supported, as known, by the revision of NOSCAR "white paper" [5]. In fact, a need for a worldwide register, a standardization of the nomenclature, safety data to be used by ethical committees in order to authorize human trials, and implementation of the interface between medical societies, industry, and regulatory offices is no longer discussed. In this field, on behalf of the EURONOTES Foundation, we have promoted a European registry of NOTES procedures (www.euronotes.world.it) for which preliminary results are now awaited.

The cooling of enthusiasm related to EA-NOS procedures has naturally forced surgeons to concentrate on techniques that could be reproduced more easily in clinical activity. This brought the interest toward the second branch of research, what we call surgical access natural orifice surgery (SA-NOS) [3], which achieves a laparoscopy-like environment by approaching the abdominal cavity with surgical devices. A wider vision of this concept allows inclusion into SA-NOS of not only transvaginal procedures but also what is increasingly mentioned in international meetings and scientific journals: single-port access (SPA) 
transumbilical surgery. Compared to EA-NOS, this approach has the advantage of not being burdened by problems related to endoscopy's defective closure in terms of infection, safety, consistent technological research, and time consumption, even if great confusion persists with respect to nomenclature or technical solutions. This advantage led to observed appreciation among surgeons. Although cholecystectomy appears to be the surgical procedure most frequently performed in the single-port fashion [6, 7], a large number of studies have been published recently showing the feasibility and safety of the use of the SPA technique for other common surgical procedures like appendectomies [8], colectomies [9-11], bariatric surgery $[12,13]$, urologic surgery [14, 15] and gynecological surgery [16, 17], Thus, it has to be said that single-port laparoscopic surgery is nothing new. It was 1992 when Pelosi [18] first described a laparoscopic appendectomy using a single umbilical puncture. Multiport single-incision transumbilical laparoscopic cholecystectomy was first described by Navarra as early as 1997 [19]. Despite this, interest in single-port surgery increased only recently. This might be the result of better establishment of laparoscopic skills over the years and extraordinary development of technology. However, it also raises concerns about a possible industry-driven interest.

There has been no discussion about the technique's numerous drawbacks. The major one is with respect to the concept of "triangulation" to which laparoscopic surgeons have grown accustomed in terms of both the instruments and scope and which is now lacking with this technique. this drawback is overshadowed by the increasing acceptability of in-line viewing, with industries concentrating satisfactorily on developing and marketing a number of curved and crossed instruments with different characteristics with the aim of restoring standard triangulation as exists in the laparoscopic environment. In fact, personal experience gained by conducting a trial on a virtual reality simulator designed for the purpose demonstrated that a short learning curve is needed for surgeons to get used to the new approach with safety and effectiveness, in direct proportion to the personal laparoscopic experience [20].

However, there are a number of different concerns associated with this procedure. The fundamental hypotheses that were the basis of interest in single-port access were that it could improve cosmetic results, decrease postoperative pain, and probably allow earlier return to work, with greater patient satisfaction. None of these points has been confirmed yet, if they ever will be. It is also clear that those who advocate patients' preference as the main reason for proposing single-port techniques forget that patients' preference is deeply influenced by the assumption that these arguments in favor of single-port surgery are correct, even though there is no realistic certainty about them.
Some of the major experts in the field of minimally invasive surgery and active researchers in the field of NOTES share the same skeptical opinion about a real benefit of the application of single-port techniques. For instance, Rattner states in a recent interview that "... it is not clear to me whether single port laparoscopy would be beneficial compared to traditional laparoscopy" [21].

In any case, we should never support the concept of even slightly improved cosmetic results over safety, the principal concern. This has implications in both the intraoperative and the postoperative period. While it is recommended not to consider conversion to standard multitrocar laparoscopy a failure, there might be an increased number of complications, as happened at the beginning of the diffusion of laparoscopy. In fact, as is often the case in similar circumstances, only a small amount of effort has been dedicated to training programs and very few simulators are available yet. Moreover, it has been advocated that a larger periumbilical incision and consequent fascial defect would imply a higher rate of incisional hernia. Although this is likely to happen, only time and acquired data will give us the answer.

For these reasons, robust studies showing that there is indeed a difference without a significant compromise of safety should be awaited before there a wide diffusion of these techniques. Studies that examine the efficacy of the many new devices on the market and those under development may help to simplify the confusing landscape of new and novel products designed for this purpose. With this as the goal, a novel multicenter randomized trial named MUSIC (MUlti-port versus SIngle-port Cholecystectomy) is about to start and will recruit 300 patients per group in a 12-month time frame. The aim of this study is to compare results of the new surgical strategy with those of the traditional four-port technique for cholecystectomy. In particular, we are going to investigate the procedures in terms of overall morbidity, while taking into consideration skin incision-related morbidity, postoperative pain, and cosmetic results, which relate to the hypothetical benefits of the new approach. Other parameters are supposed to be unchanged, considering the evidence from recent literature. The study is supported by the European Association for Endoscopic Surgery, received the approval of the local ethical committee, and is registered with Clinical Trials (U.S. International Clinical Trials Databank, U.S. National Institutes of Health, ID-code NCT01104727). This and similar studies will help us understand the risks, benefits, and potentials of this new frontier of laparoscopy.

The significant amount of research and development in this growing field may in any case lead to an improvement in our operating platform whereby new devices emerge that are completely different from the laparoscopic tools we currently use. 
Disclosures Prof. Alberto Arezzo and Prof. Mario Morino have no conflicts of interest or financial ties to disclose.

\section{References}

1. Buess G, Theiss R, Günther M, Hutterer F, Pichlmaier H (1985) Endoscopic surgery in the rectum. Endoscopy 17:31-35

2. Kalloo AN, Singh VK, Jagannath SB, Niiyama H, Hill SL, Vaughn CA, Magee CA, Kantsevoy SV (2004) Flexible transgastric peritoneoscopy: a novel approach to diagnostic and therapeutic interventions in the peritoneal cavity. Gastrointest Endosc 60:114-117

3. Vettoretto N, Arezzo A (2010) Human natural orifice translumenal endoscopic surgery: on the way to two different philosophies? Surg Endosc 24:490-492

4. Della Flora E, Wilson TG, Martin IJ, O'Rourke NA, Maddern GJ (2008) A review of natural orifice translumenal endoscopic surgery (NOTES) for intra-abdominal surgery: experimental models, techniques, and applicability to the clinical setting. Ann Surg 247:583-602

5. Hawes RH (2008) Transition from laboratory to clinical practice in NOTES: role of NOSCAR. Gastrointest Endosc Clin N Am 18:333-341

6. Cuesta MA, Berends F, Veenhof A (2008) The "invisible cholecystectomy": a transumbilical laparoscopic operation without scar. Surg Endosc 22:1211-1213

7. Zhu JF, Hu H, Ma YZ, Xu MZ (2008) Totally transumbilical endoscopic cholecystectomy without visible adominal scar using improved instruments. Surg Endosc 23:1781-1784

8. Ates O, Hakguder G, Olguner M, Akgur FM (2007) Single-port laparoscopic appendectomy conducted intracorporeally with the aid of a transabdominal sling suture. J Pediatr Surg 42:1071-1077

9. Remzi FH, Kirat HT, Geisler K (2008) Single-port laparoscopy in colorectal surgery. Colorectal Dis 10:823-826
10. Ramos-Valadez DI, Patel CB, Ragupathi M, Bartley Pickron T, Haas EM (2010) Single-incision laparoscopic right hemicolectomy: safety and feasibility in a series of consecutive cases. Surg Endosc 24(10):2613-2616

11. Remzi FH, Kirat HT, Geisler DP (2010) Laparoscopic single-port colectomy for sigmoid cancer. Tech Coloproctol 14(3):253-255

12. Texeira J, McGill K, Binenbaum S, Forrester G (2009) Laparoscopic single-site surgery for placement of an adjustable gastric band: initial experience. Surg Endosc 23:1409-1414

13. Saber AA, Elgamal MH, Itawi EA, Rao AJ (2008) Single incision laparoscopic sleeve gastrectomy (SILS): a novel technique. Obes Surg 18:1338-1342

14. Kaouk JH, Goel RK, Haber GP, Crouzet S, Desai MM, Gill IS (2008) Single-port laparoscopic radical prostatectomy. Urology 72:1190-1193

15. White WM, Haber GP, Goel RK, Crouzet S, Stein RJ, Kaouk JH (2009) Single-port urological surgery: single-center experience with the first 100 cases. Urology 74:801-804

16. Yoon BS, Park H, Seong SJ, Park CT, Park SW, Lee KJ (2010) Single-port laparoscopic salpingectomy for the surgical treatment of ectopic pregnancy. J Minim Invasive Gynecol 17:26-29

17. Yoon G, Kim TJ, Lee YY, Kim CJ, Choi CH, Lee JW, Kim BG, Bae DS (2010) Single-port access subtotal hysterectomy with transcervical morcellation: a pilot study. J Minim Invasive Gynecol 17:78-81

18. Pelosi MA, Pelosi MA III (1992) Laparoscopic appendectomy using a single umbilical puncture (minilaparoscopy). J Reprod Med 37:588-594

19. Navarra G, Pozza E, Occhionorelli S, Carcoforo P, Donini I (1997) One-wound laparoscopic cholecystectomy. Br J Surg 84:695

20. Rimonda R, Tang B, Brown S, Cuschieri A (2010) Ergonomic performance with crossed and uncrossed instruments in SinglePort laparoscopic Surgery. Surg Endosc 24:S493-S494

21. Rattner D (2007) Single port surgery and NOTES: competition or transition? WeBSurg.com Nov 2007;7(11). Available at http://www. eats.fr/doi-vd02en2227rattner3e.htm 